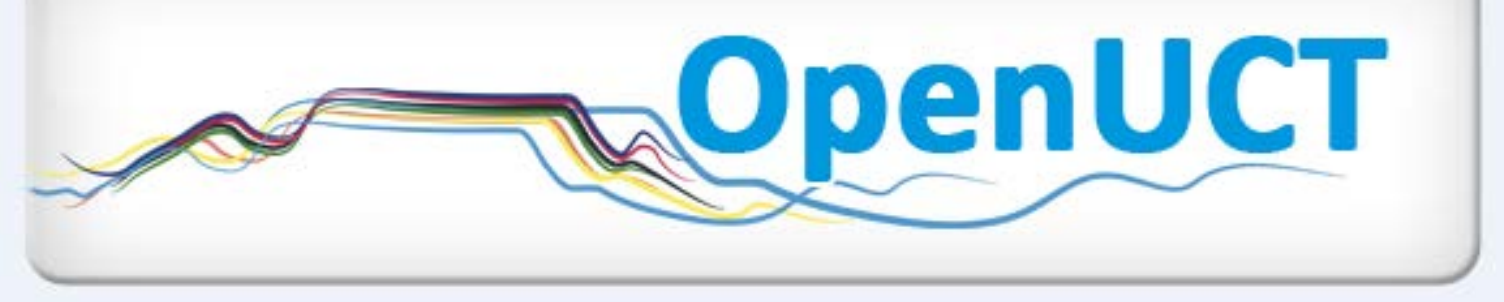

This is the post-print of Shay, S. 2008. Beyond social constructivist perspectives on assessment: the centring of knowledge. Teaching in Higher Education. 13(5): 595-605. DOI: 10.1080/13562510802334970.

It is made available according to the terms of agreement between the author and the journal, and in accordance with UCT's open access policy available:

http://www.openuct.uct.ac.za/sites/default/files/UCTOpenAccessPolicy.pdf, for the purposes of research, teaching and private study. 


\title{
Beyond social constructivist perspectives on assessment: the centring of knowledge
}

\author{
Suellen Shay* \\ Centre for Higher Education Development, University of Cape Town, Rondebosch, South Africa

\begin{abstract}
Over the past few decades assessment has been heralded for its key role in the improvement of teaching and learning. However, more recently there have been expressions of uncertainty about whether assessment is in fact delivering on its promised potential. Against this backdrop of uncertainty and circumspection this paper offers a critical reflection on higher education assessment discourses with a particular focus on the discourse of criterion referenced assessment. The central argument is that while the social constructivist perspective has significantly illuminated our understanding of assessment, inadvertently the very object of assessment Á knowledge Á has been eclipsed. I propose that a fruitful way forward for our assessment practices is the centring of disciplinary forms of knowledge as an explicit component of the object of our assessment. Drawing on sociologists of education Á Basil Bernstein and Karl Maton Á I stake out some of the theoretical ground for reconceptualising the relationship between knowledge and assessment.
\end{abstract}

Keywords: assessment; knowledge; sociology; criterion-referenced

\section{Introduction}

It has become a fairly common refrain in the educational development literature to acknowledge that there is a crisis in higher education assessment practice (Knight 2002a,b; Linn 2000; Pearson et al. 2001). Knight (2002a) who argues this most forcefully gives 25 reasons why the results of our summative assessments are not sufficiently valid for the range of purposes for which they are used. And yet, the educational development community has strongly advocated for the central role that assessment can play in both the enhancement of teaching and learning as well as the assurance of quality (Biggs 1996; Brown and Knight 1994). We have confidently asserted that given its powerful 'backwash' effect on curriculum and student learning, there can be no single more powerful form of leverage on curriculum improvement and student learning than assessment. These reform mantras have however lost some of their convincing ring. There appears to be within some quarters of the educational development community less certainty about assessment's leverage on curriculum, a quiet scepticism about its role in quality assurance and in general a greater awareness of its limited role in educational reform.

This backdrop of uncertainty and circumspection provides an opportunity for critical reflection on our assessment discourses and this paper is a contribution towards this end. The central argument is that while the social constructivist perspective has significantly illuminated our understanding of assessment, inadvertently the very object of assessment Á knowledge Á has been eclipsed. I use the term 'social constructivist perspective' to 
encapsulate two theoretical strands, the socio-cultural strand which emphasises the situatedness of practice and the constructivist strand which emphasises the constructedness of knowledge (Packer and Goicoechea 2000). Our ability as a higher education community to assess complex performances in increasingly meaningful ways requires a more sophisticated understanding of the forms of knowledge inherent in the disciplines and their requisite performances. For a better understanding of these disciplinary forms of knowledge, we need to move beyond social constructivism.

This argument unfolds in three parts. In part one I review some of the recent literature on the use of criterion-referenced assessment to illustrate the ontological conundrum that assessment discourse currently finds itself in. While this literature is suggestive of a 'knowledge problem', the analysis is not taken far enough. The second part briefly traces assessment's journey into and through the current 'constructivist drift'. Drawing on sociologists of education Muller (2000), Maton (2000, 2006, 2007), and Moore (2007), I propose that while important epistemological gains have been made from social constructivist perspectives, knowledge itself has been taken for granted. In the third part of the paper, drawing on the work of Basil Bernstein and Karl Maton, I preview what a more critical realist approach to educational knowledge might have to offer for assessment and a re-conceptualisation of assessment criteria in particular.

Before moving into the substantive part of the argument, I draw on a study by Woolf (2004) to illustrate the difficulty in which the educational development assessment community finds itself. Woolf's study forms part of a bigger project of the Student Assessment Classification Working Group. His investigation compares the assessment criteria for final year projects in two disciplines (Business and History) across a small sample of UK universities. The assessment criteria documentation collected for the study contains the list of desirables commonly found in published marking guides for students. They include things such as: clear statement of aims, appropriate underpinning of theory, critical analysis, supporting evidence, etc . . . Given the assumption of very different 'cultural differences' between the disciplines of History and Business, Woolf hypothesised that the assessment criteria for the two different disciplines would be different. However, contrary to expectation, he reports that the assessment criteria were strikingly similar. While both sets of criteria refer to subject knowledge, they do not formally assign any weighting to a demonstration of this knowledge; the criteria are more a reflection of 'general academic and intellectual skills' (484). He concludes from this seeming similarity that 'the requirements for a successful project in business or history are essentially the same' (485). I will return to this case later in the paper, but for now I ask, if these disciplines draw on very different bodies of knowledge, why are these differences not reflected in the assessment criteria? Bernstein (2000) argues that instructional discourses (for example, published assessment criteria) are always embedded in a regulative discourse. The question to which I return later is, what is regulating our current assessment discourse?

I now turn to the substantive argument as outlined above.

\section{Assessment criteria: the knowledge problem}

As noted earlier the educational development community have for some time been advocating for the powerful leverage that assessment has on student learning and curriculum improvement. Central to this improvement agenda is advocacy for criterionreferenced assessment, that is, the assessment of student performance against clearly specified 'measures' or statements of expectation. The articulation of assessment criteria has become a sine qua non for good assessment practice. There are numerous accounts for 
ways in which assessment criteria enhance learning and teaching (see Gosling and Moon 2002 , for one example). They result in greater self-awareness on the part of staff who design them; they enable students to understand and internalise the expectations; they assist staff in giving feedback; they provide a basis for justification in case of appeals. In addition to their role in enhancing learning, assessment criteria are believed to play an important role with respect to quality assurance and enhancement, assisting courses, programmes and institutions to measure the extent to which learning outcomes have been achieved (Banta 2007). Thus one finds in South Africa and other parts of the world, at every level of policy, from national to departmental level, the requirement for assessment criteria to be made more explicit.

There is little evidence, however to suggest that criterion referenced assessment has improved student learning or strengthened the overall reliability of assessment. Some have even argued that the current trend of making assessment criteria more explicit may have a deleterious effect on student learning (Gonzalez-Arnal and Burwood 2003; Norton 2004). A review of recent literature offers a wide range of documented difficulties in the use of criterion-referenced assessment. For example, the term 'criterion' means different things in different contexts (Sadler 2005; Woolf 2004). In some cases criteria refer to the desirable qualities, in other cases they refer to standards of achievement. There is also the problem that assessment criteria often do not indicate weighting, that is, the comparative importance of one in relation to others. The formulation of the 'criteria' suggests a relativity which may make judgement difficult. For example, Woolf (2004) gives an example of an assessment criterion formulated as 'students are to synthesise an appropriate range of material' Á but what determines 'appropriate'? There are no benchmarks for securing what appropriate might mean. In addition, numerous studies have focused on the problems of the consistent application of the criteria to student performance (Reed et al. 2003; Shay 2005). The challenges of achieving reliability in turn raise questions about the meaningfulness of the aggregated scores in the quest for standardisation across courses, programmes, and institutions (Knight 2002a,b; O'Donovan, Price, and Rust 2004).

While the problems with assessment criteria are well-documented and there appears to be some degree of consensus on what is not working, there is less clarity and consensus on, firstly, the underlying reasons for these problems, and, secondly, possible proposals for how we 'rescue' the assessment enterprise.

For some the problem lies is in the criteria themselves, that they are not formulated with sufficient clarity and accuracy. The solution therefore is that greater effort is needed to produce more clear and precise criteria for students, tutors, staff, external examiners and other stakeholders (Woolf 2004). Others argue that the criteria will never be precise enough. They argue that attempts to achieve greater precision are a self-defeating exercise (O'Donovan, Price, and Rust 2004). What is needed instead is meaningful understanding and application of assessment criteria within an interpretive community or community of practice. The emphasis is on participatory processes which enable the co-construction and application of meaningful criteria (O'Donovan, Price, and Rust 2004; Rust, O'Donavan, and Price 2005).

A careful review of this literature also points to another problem which is implied in some cases, explicitly stated in others: the problem is that our assessment criteria lack substantive reference points. In this vein, Sadler (2005) argues that the problem with assessment criteria is the invisibility of our standards. He defines 'standards' as fixed reference levels of attainment (193), as 'the recognised measure of what is adequate for some purpose, so established by authority, custom, or consensus' (189). Sadler argues that the set of standards implied in our assessment judgements have no 'external anchorage', 
that is, 'the standards are not conceptualised as having an existence or relevance separately from the context of the teaching team, the course as it was taught and its current students' (190). However, it is not clear from Sadler's argument what these standards might be and what might constitute such an anchor point. He tantalisingly points to disciplinary knowledge as the primary basis for standards but the argument is not elaborated.

Other authors are more explicit that the problem with our assessment criteria is a knowledge problem Á I focus specifically here on the collection of articles by O'Donovan, Price, and Rust (O'Donovan, Price, and Rust 2004; Price 2005; Rust, O'Donavan, and Price 2005). O'Donovan, Price, and Rust (2004) begin by noting the move away from the 'positivist' view of knowledge as 'an objectified and monistic absolute truth' (328) in contrast to a more social-constructivist approaches where learners 'actively make sense of new knowledge and integrate this knowledge with previously held understanding' (329). Central to their argument is Polanyi's well-known distinctions between explicit and tacit knowledge Á the former refers to 'knowledge that can be captured and codified into rules, procedures, manuals . . . easy to disseminate', the later refers to 'knowledge which is learned experientially . . . cannot be easily articulated and is elusive' (O'Donovan, Price, and Rust 2004, citing Polanyi 1958). They argue that the problem inherent in articulating assessment standards and criteria is the tacit nature of the knowledge (329). The focus of their concern, however is not disciplinary knowledge but knowledge of assessment and its largely tacit dimension. Having identified the tacit nature of assessment as the problem, the suggested solution focuses on the processes which academic communities can embark on to disseminate this tacit knowledge to one another and to students through a range of knowledge transfer processes (O'Donovan, Price, and Rust 2004).

While I fully accept, indeed have argued myself, that academics' professional judgements about student performance are deeply tacit and thus difficult to articulate (Shay 2004, 2005), what is puzzling is the silence with respect to disciplinary knowledge. I suggest that the problem with our assessment criteria is more fundamental than the problems articulated above. I argue that our assessment criteria are manifestations of an instructional discourse that is embedded in a particular regulative discourse of constructivism which has eclipsed disciplinary knowledge. Our criteria have no external anchorage (to borrow from Sadler) in the regulative discourse of the discipline.

Returning to Woolf's study (2004): in the examples of the departmental assessment criteria presented by Woolf, these criteria offer at best only a very partial view on what is valued by academics when they set academic projects. At best they say something about the practical or procedural kinds of knowledge required for project writing, for example, the need for argument, clear presentation, accurate citation and referencing. This would explain why the criteria are so similar across the two disciplines Á in procedural terms, irrespective of the discipline, as Woolf points out 'a project is a project is a project' (485). But this does not lead to the conclusion that the requirements for projects are the same in the two disciplines. The reason for the similarity is that these criteria are completely silent about the discursive or propositional knowledge required for a successful project, in other words, the forms of knowledge valued in the fields of History and Business.

This might explain therefore why the proliferation of statements of learning outcomes and published assessment criteria fail to contribute to reliability in any convincing way. The common admission by academics to the use of 'gut-feel' and intuition is testimony to the existence of other criteria which have their legitimacy in the reservoirs of knowledge from which academics draw when making professional judgements. What is lacking in our assessment criteria discourse is a language of description to talk about the valued forms of 
disciplinary knowledge. The extent to which this knowledge is explicit or tacit is a matter to be researched, rather than assumed.

I know turn to briefly trace assessment's philosophical journey into and through this ontological conundrum.

\section{The constructivist drift}

Looking back over the past 50 years, one can trace the winds of philosophical change on educational assessment. Starting from its early roots in logical positivism to more recent social-constructivist influences, the interest of this brief overview is the object of assessment. What is the field of educational assessment making claims about? When we assess, what are we assessing? Different philosophical paradigms have had profound (though often taken for granted) implications on what we think we are assessing (a matter of ontology) and how we go about assessing (a matter of epistemology). Are we assessing knowledge, if so, what knowledge? Are we assessing knowers? Are we assessing knowing? What might be the relationships between these three different possible 'objects'? Answers to these questions point to a longer-term theoretical project which is beyond the scope of the more modest objectives of this paper. However, this overview lays out some key signposts to which a theory of knowledge for assessment must return.

In his classic work on validity theory, Messick (1989) traces the philosophical shifts in psychological and educational measurement from its early roots in logical positivism through to what he calls constructivist realism. In the former the 'subject' (the assessor) observed and recorded information about an object (the assessed). These 'objects' were referred to as constructs; a construct refers to a trait or disposition that individuals are said to possess, for example, general intelligence, motivation, critical reasoning. The validity of the observations was a matter of empirical verifiability and the goal was the development of theoretically robust constructs. In this view of science the object of assessment is conceptualised as non-social (Sayer 1992).

To escape, on the one hand, from the naive realism which informed early under-" standings of assessment, and to avoid on the other hand the threats of relativism, Messick (1989) argues for a constructivistÁrealist position. It is realist because it insists on independent external objects of assessment ('traits and other causal entities exist outside the theorist's mind', 29). It is a constructivist-realism because it assumes that these constructs cannot be directly interpreted but can only be viewed through the 'constructions of that mind' (29). However, given the interests of this overview, it is important to note that while the assessor is acknowledged as socially situated, the object of assessment Á so-called 'constructs' Á remain conceptualised as a non-social object.

A number of educational assessment scholars have critiqued the powerfully enduring and problematic influence of psychometrics on classroom assessment practice (Broadfoot 1996; Gipps 1999; Shepard 2000). As a challenge to the measurement paradigm, these scholars have called for a new assessment paradigm with a different set of starting points. There are two significant strands to this critique. Drawing on the social theories of Bourdieu, Foucault and Bernstein, the socio-cultural strand pushes more strongly the social-situatedness of the assessor. Not only are assessments not neutral observations, assessment is a mechanism for power and control, and ultimately cultural and social reproduction (Broadfoot 1996; Gipps 1999). Drawing from constructivist theories of learning, the social constructivist strand problematises the conceptualisation of the 'object' as non-social. The constructs of interest to psychometric testing do not have an independent status; they are embodied in social beings who themselves are in relation 
with and responding to other social beings Á peers, teachers, family and not least of all the assessor. Knowledge is not 'out there', it is constructed thus better conceptualised as 'knowing'. Furthermore, knowing is not an individual cognitive activity, it is social (Shepard 2000). The emphasis of the new assessment paradigm is on the communal acts of constructing knowledge. Thus in the shift from constructive realism to social constructivism, the object of assessment shifts from non-social constructs to socially situated knowers and their acts of knowing.

There is no question about the significance of this social constructivist turn on assessment. It has served to destabilise deeply entrenched premises about the neutrality of 'subjects' and the non-social status of 'objects'. The centring of learners and learning has foregrounded the formative purposes of assessment, reasserting assessment as part of the teaching and learning process. But in the reassertion of learners and learning, we need to ask ourselves, what happened to knowledge?

In his critique of standpoint theories of sociology of education, Moore (2007) argues that the problem with the relativising positions of constructivism is that the very status of knowledge is compromised, 'knowledge is experientially conflated with knowing and it is always someone's knowing' (28). Drawing on Bhaskar, Moore suggests that critical realism offers an alternative view of knowledge. Without losing the important epistemological gains made by social constructivism, I argue that we need to move beyond it. Assessment needs to be re-anchored to realist understandings of knowledge. This is not to hearken back to correspondence theories of knowledge, nor to deny the 'intrinsic "sociality" of knowledge' (Muller 2000, 2 italics in original). It is rather a quest for a theory which grants knowledge a status independent of knowers. A view of knowledge as objective (though always socially mediated) might illuminate significant distinctions between the forms of knowledge that constitute, for example, a History curriculum from Business Studies.

\section{What theory of knowledge will do?}

I have argued that academics' professional judgements about what constitutes legitimate texts flow from their reservoirs of disciplinary knowledge. It is at least in part from this knowledge reservoir that the 'standards' called for earlier emerge. With respect to this knowledge two things are needed: firstly, a language of description for disciplinary knowledge and secondly, a better understanding of the relationship between these disciplinary forms of knowledge and assessment.

With respect to the first requirement, we need ways of classifying and describing the differences between disciplinary forms of knowledge. Biglan's (1973a, 1973b) four quadrant typology (hard pure, soft pure, hard applied, soft applied) remains the most commonly used classification system for analysis of disciplinary differences. The hard/soft dimension refers to the discipline's paradigmatic status, that is, the degree of consensus among scholars concerning the relevant problems and appropriate methodological procedures. 'Hard' refers to high levels of consensus as one would find in the physical sciences, and 'soft' refers to low levels as one would find in sociology or philosophy. The pure/applied dimension refers to the level of application. Becher (1994) and Becher and Trowler (2001) have elaborated on Biglan's typology to include the nature of knowledge or epistemologies of these different disciplinary groupings. The hard disciplines are characterised by knowledge which is cumulative and atomistic in nature, in contrast to soft disciplines where knowledge is iterative and holistic in nature. However, Becher and Trowler (2001) note that the tidiness of this classification system is complicated by analysis at the level of specialisation within the discipline. In fact they argue that epistemological 
differences within a discipline may result in specialists having more in common with someone from another discipline than within their own. Given the rapid diversification and growth of knowledge, further analytical work on disciplinary forms of knowledge needs to assume these complications are the norm rather than exception. It also suggests that a more fine-grained set of analytical tools is needed than what the BiglanÁBecher typology has to offer.

With respect to our need for a better understanding of the relationship between disciplinary forms of knowledge and assessment, Neumann (2001) and Neumann, Parry, and Becher 2002) apply the BiglanÁBecher typology to explore differences in teaching and learning, including assessment. The literature reveals some predictable trends: the hard pure fields prefer specific, closely focused examination questions in contrast to the soft pure which favour broad essay type questions. Marking guidelines are more likely to be found in the soft pure field where responses are more open to interpretation. These findings are somewhat limited by the bluntness of the BiglanÁBecher typology (which Neumann acknowledges is more of a heuristic) as well as the predominant focus on assessment method rather than the underlying values which inform the criteria. What is needed is a theoretical framework which provides more fundamental explanations for the relationship between knowledge and the evaluative criteria Á evaluative criteria in lieu of assessment criteria signals a discursive shift away from explicit measurables to underlying values. I suggest that Bernstein's pedagogic device (2000) offers an explanatory model for this relationship and his work on knowledge structures is a good starting place which has been usefully elaborated by Karl Maton's $(2000,2006,2007)$ work on legitimation codes. In this final section, I stake out some of the theoretical ground for further research on the relationship between assessment and disciplinary forms of knowledge.

Bernstein's (2000) pedagogic device models the relationship between the field of knowledge production, the field of transmission where knowledge is recontextualised into curriculum and pedagogy, and the field of reproduction where knowledge is legitimated through assessment (or Bernstein's preferred term 'evaluation'). Bernstein's pedagogic device is a 'relay' constituted by a series of rules which determine how knowledge is produced, recontextualised and evaluated. The distributive rules determine which knowledge is deemed more or less worthwhile. The recontextualising rules transform knowledge into curriculum and pedagogic communication, and the evaluative rules legitimate performances and 'stipulat(e) the specialised consciousness that should result' (Maton and Muller 2007, 8). Thus the evaluative rules are the sum of all the rules setting the criteria for what counts as legitimate texts. It is important to note that 'texts' for Bernstein is used in the broadest sense encompassing not only performances for grades but 'anything that attracts evaluation' (18), for example, use of the body, manner of speaking, even dress. Crucially therefore, the specialisation of certain kinds of knowledge is at the same time the specialisation of certain kinds of knowers. Evaluative criteria not only legitimate texts, they legitimate knower identities.

Thus Bernstein's pedagogic device offers a theoretical frame for conceptualising the relationship between knowledge and evaluative (assessment) criteria Á these criteria have their epistemic roots in knowledge from its site of production to its recontextualising into curriculum and transmission through pedagogy. Reflecting on Bernstein's focus on evaluative rules, Maton and Muller (2007) comment, 'if the criteria (that these rules) construct bear no relation to their parent knowledges ... then schooling will undermine its role as a relay of specialised knowledges' (19). Bernstein's model provides an explanatory model not only for knowledge and evaluative criteria but also knowers. Knowledge specialises knowers through the evaluative criteria. 
In his last project Bernstein turned his attention to making the knowledge object visible, a project which had up to then been neglected in his own work (Bernstein 2000). Drawing on Durkheim, he argues for two epistemologically different forms of knowledge which he calls discourses Á vertical and horizontal. Horizontal discourse refers to everyday knowledge, knowledge which is context-dependent, procedural, and segmented. In contrast, vertical discourse is theoretical knowledge, knowledge which is abstract and generalisable. Vertical discourse, he argues, has two different kinds of structure Á a hierarchical knowledge structure and a horizontal knowledge structure. The former (visually illustrated as a triangle) refers to a 'form of knowledge which attempts to create very general propositions and theories, which integrate knowledge at lower levels, and in this way shows underlying uniformity across an expanding range of apparently different phenomena' (161). This knowledge structure is what one might find in the physical sciences such as Physics and Chemistry. In contrast a horizontal knowledge structure consists of 'a series of specialised languages with specialised modes of interrogation and criteria for the construction and circulation of texts' (161) typical of what one would find in the field of, for example, English Literature and the Humanities and Social Sciences more generally.

With respect to a theory of knowledge for assessment, Bernstein's model is useful in three ways. Firstly, knowledge as an object is made visible (Maton and Muller 2007, 20). It has an identity distinct from knowers and knowing. It has both social and epistemic dimensions. Secondly, Berntein's knowledge structures have implications for evaluative rules. Hierarchical knowledge structures are typically strongly classified Á that is, there are strong boundaries within and between the knowledge domains with relatively wellestablished criteria for evaluating what constitutes legitimate text. Horizontal knowledge structures are typically weakly classified, that is, boundaries between knowledge domains are more permeable and evaluative criteria less established, requiring negotiation (Bernstein 1975; Shay, 2008). Thirdly, Bernstein's model points to ways in which knowledge structures specialise consciousness and thus knower identities. Critical to the specialisation of identity is the role of the evaluative criteria which operate as a ruler of consciousness (Bernstein 2000).

Maton's $(2000,2006,2007)$ interest is in how knowledge structures specialise knowers since, as he argues, 'issues of who knows what and how have become crucial far beyond the academy' (Maton 2006, 1 italics in original). How this specialisation happens requires an analysis of the underlying principles which structure what is considered legitimate, what he refers to as legitimation codes. These codes are constituted by two analytically distinct sets of relations, the epistemic and the social (Maton 2000, 154). The former refers to the relation between the knowledge claim and its object (what the knowledge claim is about). The latter refers to the relation between the knowledge claim and the subject (the one making the claim). In contrast to constructivism which collapses knower, knowledge and known, Maton's critical realist position insists on the analytical distinctness of the social and epistemic dimensions of knowledge.' . . . every practice, belief or knowledge claim is about or oriented towards something and by someone ...' (Lamont and Maton, forthcoming, italics added). It is possible therefore to identify knowledge structures which have strong epistemic relations (ER') Á where the what you know and the how of what you know is paramount, in contrast to knowledge structure which have strong social relations (SR') Á where who you are and what dispositions you possess are valued.

Maton's legitimation code theory provides a method for analysing underlying principles which constitute intellectual fields and educational knowledge. A 'knowledge code' (ER', SR () emphasises the possession of knowledge (procedures, skills, techniques), for example, as might be expected in the natural and physical sciences. 
A 'knower code' (ER (, SR') emphasises the disposition or 'gaze' of knowers, as might be expected in the arts and humanities. While one might find a dominant code in the field of Physics or Literary Studies, the legitimation code of a Health Sciences curriculum might reveal interesting contestations in the underlying principles where the traditional biophysical model of health is being challenged by more biopsycho-social understandings.

Maton's legitimation codes provide a potentially useful theory for conceptualising the evaluative criteria which assessors' bring to bear on student performance. These codes conceptualise different 'rulers of achievement' (Lamont and Maton, forthcoming). We could start by asking whether a particular curriculum of, for example, History or Business Studies, is dominated by a knowledge code or a knower code. In what ways do the evaluative criteria Á which emerge from the code Á specialise knowers in particular ways? A theoretical frame which allows these kinds of questions to emerge (and more) promises to bring enriched understanding to the role of assessment.

\section{Conclusion}

This paper started by noting a growing concern within the educational development community that assessment may be failing to fulfil its promised role as a catalyst for improving student learning. A review of some recent studies on the use of criterionreferenced assessment suggests that our assessment criteria discourse have no anchoring in the disciplinary forms of knowledge which constitute higher education curricula. Although we have benefited significantly from the insights of assessment as a social practice, the centering of knowers and knowing has been at the expense of knowledge. To centre knowledge Á to give it an identity distinct from knowers and knowing Á will require a realist theory of knowledge and I have proposed that the work of Bernstein on knowledge structures and Maton's legitimation code theory may be a fruitful place to begin.

One of the implications of this critique, is that contrary to the educational development wisdom, assessment may not be the place to start if we want to improve the quality of teaching and learning. A better starting place may be curriculum and its constituent forms of knowledge. With respect to this starting point the educational development community has a very limited theory and language with which to understand, describe and explain the forms of disciplinary knowledge which are the very object of our assessment. Herein, lies an area wide open for research.

\section{Acknowledgements}

I am grateful to the National Research Funding of South Africa for the funding to present a version of this paper at the Improving Student Learning Conference in Dublin, Ireland in September 2007.

\section{References}

Banta, T. 2007. Using electronic portfolios to assess learning at IUPUI. REAP07: Assessment design for learner responsibility. Keynote Presentation, University of Strathclyde, UK.

Biglan, A. 1973a. Relationships between subject matter characteristics and the structure and output of university departments. Journal of Applied Psychology 57, no. 3: 204 Á13.

***.1973b. The characteristics of subject matter in different academic areas. Journal of Applied Psychology 57, no. 3: 195Á203.

Becher, T. 1994. The significance of disciplinary differences. Studies in Higher Education 19, no. 2: 151 Á62.

Becher, T., and P. Trowler. 2001. Academic tribes and territories: Intellectual enquiry and the cultures of disciplines. 2nd ed. Buckingham, UK: Society for Research into Higher Education \& Open University Press. 
Bernstein, B. 1975. Class, codes and control. London: Routledge \& Kegan Paul.

$\star \star \star$. 2000. Pedagogy, symbolic control and identity: Theory, research and critique. Lanham, MD: Rowman \& Littlefield.

Biggs, J. 1996. Assessing learning quality: Reconciling institutional, staff and educational demands. Assessment and Evaluation in Higher Education 21, no. 1: 5Á15.

Brown, S., and P. Knight. 1994. Assessing learners in higher education. London: Kogan Page.

Broadfoot, P. 1996. Education, assessment and society: A sociological analysis. Buckingham, UK: Open University Press.

Gipps, C. 1999. Socio-cultural aspects of assessment. Review of research in education/AERA, no. 24: 355Á92.

Gonzalez-Arnal, S., and S. Burwood. 2003. Tacit knowledge and public accounts. The Journal of Philosophy of Education 37, no. 3: 377 Á91.

Gosling, D., and J. Moon. 2002. How to use learning outcomes and assessment criteria. 3rd ed. London: SEEC.

Knight, P. 2002a. The Achilles' heel of quality: The assessment of student learning. Quality in Higher Education 8, no. 1: 107Á15.

***. 2002b. Summative assessment in higher education: Practices in disarray. Studies in Higher Education 27, no. 3: 275Á86.

Lamont, A., and K. Maton. Forthcoming. Choosing music: Exploratory studies into the low uptake of music GCSE. British Journal of Music Education.

Linn, R. 2000. Assessments and accountability. Educational Research 29, no. 2: 4Á16.

Maton, K. 2000. Languages of legitimation: The structuring significance for intellectual fields of strategic claims. British Journal of Sociology of Education 21, no. 2: 147 Á67.

***. 2006. On knowledge structures and knower structures. In Knowledge, power and educational reform: Applying the sociology of Basil Bernstein, ed. M. Moore, J. Arnot, H. Beck, and Daniels, 44Á59. London: Routledge.

***. 2007. Knowledge-knower structures in intellectual and educational fields. In Language, knowledge and pedagogy: Functional linguistics to sociological perspectives, ed. F. Christie and J. Martin, 87Á108. London: Continuum.

Maton, K., and J. Muller. 2007. A sociology for the transmission of knowledge. In Language, knowledge and pedagogy: Functional linguistics to sociological perspectives, ed. F. Christie and J. Martin, 14Á33. London: Continuum.

Messick, S. 1989. Meaning and values in text validation: The science and ethics of assessment. Educational Researcher 18, no. 2: 5Á11.

Moore, R. 2007. Going critical: The problem of problematizing knowledge in education studies. Critical Studies in Education 48, no. 1: 25Á41.

Muller, J. 2000. Reclaiming knowledge: Social theory, curriculum and education policy. London: Routledge Falmer.

Neumann, R. 2001. Disciplinary differences and university teaching. Studies in Higher Education 26, no. 2: $135 A ́ 46$.

Neumann, R., S. Parry, and T. Becher. 2002. Teaching and learning in their diciplinary contexts: A conceptual analysis. Studies in Higher Education 27, no. 4: 405Á17.

Norton, L. 2004. Using criteria as learning criteria: A case study in psychology. Assessment and Evaluation in Higher Education 29, no. 6: 687Á702.

O'Donovan, B., M. Price, and C. Rust. 2004. Know what I mean? Enhancing student understanding of assessment standards and criteria. Teaching in Higher Education 9, no. 3: 325Á35.

Packer, M.J., and J. Goicoechea. 2000. Sociocultural and constructivist theories of learning: Ontology, not just Epistemology. Educational Psychologist 35, no. 4: 227 Á41.

Pearson, D., S. Vyas, L. Sensale, and Y. Kim. 2001. Making our way through the assessment and accountability maze: Where do we go now? The Clearing House 74, no. 4: 175 Á82.

Polanyi, M. 1958. Personal knowledge: Towards a post-critical philosophy. London: Routledge and Kegan Paul.

Price, M. 2005. Assessment standards: The role of communities of practice and the scholarship of assessment. 'Assessment \& Evaluation in Higher Education, 215 Á30.

Reed, Y., S. Granville, H. Janks, P. Makoe, P. Stein, S.W. Van Zyl, and M. Samuel. 2003. (Un)reliable assessment: A case study. Perspectives in Education 21, no. 1: 15Á28. 
Rust, C., B. O'Donavan, and M. Price. 2005. A social constructivist assessment process model: How the research literature shows us this could be best practice. Assessment \& Evaluation in Higher Education 30, no. 3: 231Á40.

Sadler, D.R. 2005. Interpretations of criteria-based assessment in grading in higher education. Assessment \& Evaluation in Higher Education 30, no. 2: 175Á94.

Sayer, A. 1992. Method in social science: A realist approach, 2nd edn. London: Routledge.

Shay, S.B. 2004. The assessment of complex performance: A socially situated interpretive act. Harvard Educational Review 74, no. 3: 307Á29.

***. 2005. The assessment of complex tasks: A double reading. Studies in Higher Education 30, no. 6: 663Á79.

***. 2008. Assessment at the boundaries: Service learning as case study. British Educational Research Journal 34, no. 4: 525Á40.

Shepard, L. 2000. The role of assessment in a learning culture. Educational Researcher. 29, no. 7: 4Á 14.

Woolf, H. 2004. Assessment criteria: Reflections on current practices. Assessment \& Evaluation in Higher Education 29, no. 4: 479Á93. 